\title{
Study of Coeliac Trunk - Length and Its Branching Pattern
}

\author{
Suman $\operatorname{Tiwari}^{1}$, K. Jeyanthi ${ }^{2}$ \\ ${ }^{I}$ (Department of Anatomy, MVJ Medical college, Bangalore India) \\ 2 (Department of Anatomy, Kempegowda Institute of Medical sciences, Bangalore India)
}

\begin{abstract}
The coeliac trunk is a surgically significant artery of the abdomen which supplies the supracolic organs. Variations of these arteries are important from a surgical perspective. In the present study, the length of coeliac trunk and its branching pattern was noted in 50 embalmed human cadavers. The length of coeliac trunk was correlated with its branching pattern. The specimens were studied by dissection method at the Department of Anatomy, KIMS and other medical colleges in and around Bangalore. The maximum number of specimens of coeliac trunk had a length ranging from 1.3-1.8 cm which was observed in 20 (40\%) specimens. $84 \%$ of the specimens studied showed trifurcation. Quadrifurcation was seen in $8 \%$, pentafurcation in $6 \%$ and bifurcation in $2 \%$ specimens. A smaller length of coeliac trunk was associated with varying branching pattern. This knowledge of the varied branching patterns forms the basis for surgical and radiological procedures in the upper abdomen.
\end{abstract}

Keywords: Branching pattern, common hepatic artery, left gastric artery, splenic artery, variations of coeliac trunk.

\section{Introduction}

The coeliac trunk is a wide ventral branch of abdominal aorta measuring about $1.25 \mathrm{~cm}$ in length and arising just below the aortic hiatus opposite the lower border of T12. It passes almost horizontally forwards and slightly right above the pancreas and splenic vein, dividing into left gastric, splenic and common hepatic arteries. [1]

The most common classical type of variation of coeliac trunk is known as trifurcation and was first observed by Haller as tripus Halleri. It was, and still is, considered to be the normal appearance of coeliac trunk. According to Haller, coeliac trunk divides into common hepatic, splenic and left gastric arteries, while the other divisions of coeliac trunk rarely occur in human populations. Past research on cadavers and living persons has shown a plethora of variations. About $15 \%$ of the population displays significant variations from the typical branching pattern.

Investigations have shown that the coeliac trunk can divide into 2-6 branches. Depending on the number of divisions that are made, there are 6 main categories of coeliac trunk variation. They are bifurcation, trifurcation, quadrifurcation, pentafurcation and even hexafurcation. One of the important variations is the origin of dorsal pancreatic artery from coeliac trunk. This variation is significant to a surgeon during different pancreatic procedures, splenectomies and resections for which knowledge of the gastric arteries is required. [2]

The variations in the anatomy of the trunk must be understood carefully to make proper adjustments in anastamosing the proper arteries in surgeries of the supracolic region. The knowledge of variations of coeliac trunk and their sub-types is fundamental for a correct pre-operative vascular planning in surgical and radiological abdominal procedures like liver transplantation and hepatic arterial infusion chemotherapy via catheters for therapy of unresectable advanced liver malignancies. [3]

Petrella [4] examined 89 cadavers and observed the length of the coeliac trunk and variation of its branches. The mean length of the coeliac trunk was $1.23 \mathrm{~cm}$ in males and $1.18 \mathrm{~cm}$ in females. In $73(82.02 \%)$ out of the 89 cadavers, the coeliac trunk emitted the left gastric, splenic and common hepatic arteries and in the remaining $16(17.98 \%)$ variations were observed.

Mburu [5] studied 123 specimens of coeliac trunk in Kenyan population and found that the coeliac trunk was trifurcated in $76(61.7 \%)$, bifurcated in $22(17.9 \%)$ and gave collateral branches in $25(20.3 \%)$. The frequency of occurance of variations of branching pattern of coeliac trunk is variable in the literature. The present work has been undertaken to describe length of coeliac trunk, variations in its branching pattern and to correlate the length of the coeliac trunk with its branching pattern in south Indian adult population.

\section{Materials and methods}

A total of 50 embalmed human cadavers were dissected. The cadavers were from south Indian adult population and comprised of 42 males and 8 females. The gross dissection was done following the guidelines of Cunningham's manual. After the peritoneum was studied the peritoneal cavity was opened. The anterior layer of peritoneum from the lesser omentum was removed close to the lesser curvature of the stomach. Left gastric 
artery was identified and traced till it curves posteriorly around the superior surface of the omental bursa. The right gastric artery was identified and traced to the proper hepatic artery. The proper hepatic artery and its branches to the porta hepatis were exposed and cleaned.

The coeliac trunk is identified and the dense autonomic plexus from its branches removed. The length of the trunk from its origin up to its emission of the first branch was measured using sliding calipers. The mean and standard deviation was calculated for the length of the trunk. The branching pattern was noted in each specimen. After observation, the moisture over the artery and nearby areas was removed with filter paper. All the specimens were duly numbered and photographed. The data obtained was recorded, analyzed and compared with that of previous studies.

Descriptive statistical analysis has been carried out in the present study. Results on continuous measurements are presented on Mean \pm SD (Min-Max) and results on categorical measurements are presented in Number (\%). Significance is assessed at $5 \%$ level of significance. Student $t$ test ( two tailed, independent) has been used to find the significance of study parameters on continuous scale between two groups (Inter group analysis) on metric parameters, Chi-square/ Fisher Exact test has been used to find the significance of study parameters on categorical scale between two or more groups.

\section{Results}

The following observations were recorded. The length of the coeliac trunk in males and females are shown in Table 1. The maximum number of specimens had a length ranging from 1.3-1.8 $\mathrm{cm}$, which was observed in $20(40 \%)$ specimens. This is followed by $0.6-1.2 \mathrm{~cm}$ which was observed in $15(30 \%)$ specimens. In $9(18 \%)$ specimens, the length was $<0.6 \mathrm{~cm}$ and in $6(12 \%)$, the length was between $1.9-2.5 \mathrm{~cm}$. Statistical analysis showed that mean length of the coeliac trunk is more in males compared to females with $P$ value of 0.304 .

The different branching patterns that were observed are shown in Table 2. Significant deviation is observed in females compared to males in branching pattern with $\mathrm{P}=0.076+$

Trifurcation was observed in $42(84 \%)$ specimens. Out of $42(84 \%)$ specimens, $40(80 \%)$ specimens showed classical trifurcation in which the coeliac trunk divided into common hepatic, splenic and left gastric arteries. $1(2 \%)$ specimen trifurcated into left gastric, splenic and right inferior phrenic arteries. The common hepatic artery in that specimen was seen arising from the superior mesenteric artery. In another $1(2 \%)$ specimen, the coeliac trunk trifurcated into common hepatic, splenic, right gastric arteries and left gastric artery arose directly from the abdominal aorta. (Fig 3) Bifurcation of the coeliac trunk into common hepatic and splenic artery was observed in $1(2 \%)$ specimen. In that specimen, the left gastric artery arose directly from the abdominal aorta. (Fig 1) Quadrifurcation and pentafurcation of the coeliac trunk was observed in $4(8 \%)$ and $3(6 \%)$ specimens respectively. In quadrifurcation and pentafurcation, the common hepatic, splenic and left gastric arteries are the constant branches with the addition of dorsal pancreatic, gastroduodenal and inferior phrenic arteries. (Fig 5\&7)

The length of coeliac trunk is correlated with its branching pattern. (Table 3) Length is significantly associated with branching pattern with $\mathrm{P}=0.001 * *$ ( $4 \times 4$ Fisher Exact test) and showed the association of varying branching pattern with smaller length of coeliac trunk.

\section{Discussion}

The studies conducted by Saeed [6] on 20 cadavers showed that in $60 \%$ of cases, the length of the coeliac trunk was between 1.3-1.8 cm. In the present study, in $40 \%$ of the specimens, the length of coeliac trunk ranged from 1.3-1.8 cm. Petrella [4] had found the mean length of coeliac trunk was $1.24 \mathrm{~cm}$ in males and 1.18 $\mathrm{cm}$ in females. The results of the present study are similar to Petrella's where the mean length was $1.24 \mathrm{~cm}$ in males and $1.01 \mathrm{~cm}$ in females.

The prevalence of variations of branching pattern of coeliac trunk noted by previous authors in their studies is summarized in Table 4. From the Table 4, it is evident that in the studies conducted by Petrella [4], Urugel [7] and the present one, except Mburu [5], above $80 \%$ of cases of coeliac trunk showed classical trifurcation.

Yildirim [8] dissected the upper abdominal region of 52 cadavers and observed in one case, a hepatosplenic trunk with the left gastric artery directly originating from the abdominal aorta. In the present study, in 2(4\%) specimens, the left gastric artery arose directly from the abdominal aorta. The left gastric artery is a mobile vessel whose origin may vary between the aorta and anywhere along the coeliac trunk up to a trifurcation. The origin of left gastric artery from the aorta has importance in operative procedures on supracolic organs, in stomach resection and during dissection of lymph nodes along this artery in gastric cancer.

Pulakunta [9] had observed the origin of inferior phrenic arteries in $4(12.5 \%)$ out of 32 cases. The present study showed the origin of inferior phrenic arteries from coeliac trunk in $5(10 \%)$ specimens. The variations of inferior phrenic arteries are important for surgeons to avoid unintentional sectioning of small 
caliber arteries during coeliac artery decompression in the compression syndrome of coeliac trunk by the median arcuate ligament. [9, 10]

All these variations have embryological basis. During development, each primitive dorsal aorta gives off ventral splanchnic arteries, lateral splanchnic arteries and somatic arteries. As the embryo continues to develop, most of the segmental arteries regress, except for the precursors of the segmental arteries to the three major mesenteric vessels. The $10^{\text {th }}$ segmental artery forms the coeliac trunk which supplies the foregut. The $13^{\text {th }}$ segmental artery becomes the superior mesenteric artery for the midgut, and the $22^{\text {nd }}$ segmental develops into the inferior mesenteric artery for the hindgut. Anatomic variations of the coeliac trunk occur as a result of developmental changes in the ventral arteries of the visceral organs. $[1,11,12]$ Some of the other important factors that cause variable anatomy of coeliac axis include rotation of the mid-gut and its physiological herniation during development, leftward migration of the spleen and haemodynamic changes in the abdominal viscera. [5]

In this study, a long coeliac trunk showed only trifurcation and coeliac trunk with a smaller length showed varying branching pattern. If coeliac trunk is of greater length than normal, the surrounding tissues could be more susceptible to disease. Patients who present with stomach pain should be evaluated for coeliac trunk compression syndrome arising from the probable existence of a congenitally formed extended coeliac trunk. [2]

\section{Conclusion}

To conclude, the coeliac trunk which is the artery of the foregut is known for its variation. The variations were seen in the length and branching pattern. The branching pattern varied from bifurcation to pentafurcation with trifurcation as a common pattern. There was a significant association between short coeliac trunk and varying branching pattern. These variations should be kept in mind during surgical and radiological procedures in upper abdomen to avoid intraoperative and post -operative complications.

\section{Acknowledgement}

I am extremely grateful to Dr. K.Jeyanthi, Associate professor, Department of Anatomy for her constant encouragement, patience and support.

I sincerely thank our principal of KIMS, Bangalore, for giving me permission to carry out the research work.

\section{References}

[1] WilliamsPL.,Bannister.L.H.,Berry.M.M.,Collins.P.,Dyson.M.,Dussek.J.E.et.al. Gray’s anatomy $38^{\text {th }}$.ed.churchill Livingstone, 2000, 1548-1552.

[2] Gielecki J., Zurada A., Sonpal N., Jabtonska B., "The clinical relevance of coeliac trunk variations." Folia Morphol. 2005; 64(3): 123-129.

[3] Iezzi.R.,Cotroneo.A.R.,Giancristofaro.D.,Santoro.M.,Storto.M.L.,"Multidetector-row CT angiographic imaging of the coeliac trunk :anatomy and normal variants." 2008; 30(4):303-310

[4] Petrella S, Rodriguez CFS, Sgrott EA, Fernandes GJM, Marques SR, Prates JC. Anatomy and variations of coeliac trunk. Int J. Morphology, 2007; 25(2): 249-257.

[5] Mburu KS, Alexander OJ, Hassan S, Bernard N. Variations in the branching pattern of the coeliac trunk in Kenyan population. Int. J. Morphol., 2010; 28(1):199-204.

[6] Saeed M, Rufal AA. Duplication of hepatic artery. Saudi J Gastroenterology 2001; 7(3):103-108

[7] Urugel MS, Battal B, Bozlar U, Nural MS, Tasar M,ORS F et al. Anatomical variations of hepatic arterial system, coeliac trunk and renal arteries: an analysis with multidetector CT angiography. British journal of radiology June 152010

[8] Yildirim M., Ozan H., Kutoglu T., Anatomic variations "Left gastric artery originating directly from the aorta." Journal of surgical and radiological anatomy, 2005; 20(4):303-305.

[9] Pulakunta T, Potu BK, Gorantla VR, Rao MS, Madhyastha S, Vollala VR. The origin of the inferior phrenic artery: a study in 32 South Indian cadavers with a review of literature. J Vasc Bras 2007; 6(3):225-230.

[10] Petrella S, Rodrigues CFS, Sgrott EA, Fernandez GJM, Marques SR, Prates JC. "Origin of inferior phrenic arteries in the coeliac trunk." Int. J. Morphology., 2006; 24(2):275-278.

[11] Douard R, Chevallier J, Delmas V, Cugnenc P. Clinical interest of digestive arterial trunk anastamoses. Surg Radiol Anat 2006; 28: 219-227.

[12] Cavdar S, Sehirli U, Pekin B. Coeliacomesenteric trunk. Clinical anatomy 1997; 10:231-234.

Table 1: Length of the coeliac trunk in males and females

\begin{tabular}{|c|c|c|c|c|c|c|}
\hline \multirow{2}{*}{$\begin{array}{l}\text { Length of trunk } \\
\text { (cm) }\end{array}$} & \multicolumn{2}{|c|}{ Male } & \multicolumn{2}{|c|}{ Female } & \multicolumn{2}{|c|}{ Total } \\
\hline & No & $\%$ & No & $\%$ & No & $\%$ \\
\hline$<0.6$ & 5 & 11.9 & 4 & 50.0 & 9 & 18.0 \\
\hline $0.6-1.2$ & 14 & 33.3 & 1 & 12.5 & 15 & 30.0 \\
\hline $1.3-1.8$ & 18 & 42.9 & 2 & 25.0 & 20 & 40.0 \\
\hline $1.9-2.5$ & 5 & 11.9 & 1 & 12.5 & 6 & 12.0 \\
\hline Total & 42 & 100.0 & 8 & 100.0 & 50 & 100.0 \\
\hline Mean \pm SD & \multicolumn{2}{|c|}{$1.24 \pm 0.51$} & \multicolumn{2}{|c|}{$1.01 \pm 0.81$} & \multicolumn{2}{|c|}{$1.20 \pm 0.56$} \\
\hline Inference & \multicolumn{6}{|c|}{ Mean length of coeliac trunk is more in males compared to females with $\mathrm{P}=0.304$} \\
\hline
\end{tabular}


Table 2: Branching pattern of coeliac trunk in males and females

\begin{tabular}{|c|c|c|c|c|c|c|}
\hline \multirow{2}{*}{ Branching pattern } & \multicolumn{2}{|c|}{ Male } & \multicolumn{2}{|c|}{ Female } & \multicolumn{2}{|c|}{ Total } \\
\hline & No & $\%$ & No & $\%$ & No & $\%$ \\
\hline Bifurcation & 0 & 0.0 & 1 & 12.5 & 1 & 2.0 \\
\hline Trifurcation & 37 & 88.1 & 5 & 62.5 & 42 & 84.0 \\
\hline Quadrifurcation & 3 & 7.1 & 1 & 12.5 & 4 & 8.0 \\
\hline Pentafurcation & 2 & 4.8 & 1 & 12.5 & 3 & 6.0 \\
\hline Total & 42 & 100.0 & 8 & 100.0 & 50 & 100.0 \\
\hline Inference & \multicolumn{6}{|c|}{$\begin{array}{l}\text { Significant deviation is observed in females compared to males in branching pattern with } \\
\mathrm{P}=0.076+\end{array}$} \\
\hline
\end{tabular}

Table 3: Correlation of length of coeliac trunk with its branching pattern

\begin{tabular}{|l|l|l|l|l|}
\hline \multirow{2}{*}{ Length } & \multicolumn{1}{|l|}{ Branching pattern } \\
\cline { 2 - 5 } & Bifurcation & Trifurcation & Quadrifurcation & Pentafurcation \\
\hline$<0.6$ & $1(100.0 \%)$ & $5(11.9 \%)$ & 0 & $3(100.0 \%)$ \\
\hline $0.6-1.2$ & 0 & $11(26.2 \%)$ & $4(100.0 \%)$ & 0 \\
\hline $1.3-1.8$ & 0 & $20(47.6 \%)$ & 0 & 0 \\
\hline $1.9-2.5$ & 0 & $6(14.3 \%)$ & 0 & 0 \\
\hline Total & $1(100.0 \%)$ & $42(100.0 \%)$ & $4(100.0 \%)$ & $3(100.0 \%)$ \\
\hline Inference & $\begin{array}{l}\text { Length is significantly associated with Branching pattern with } \mathrm{P}=0.001 * *(4 \times 4 \text { Fisher Exact } \\
\text { test })\end{array}$ \\
\hline
\end{tabular}

Table 4: Comparison of branching pattern of coeliac trunk found in earlier studies with the present study

\begin{tabular}{|l|l|l|l|}
\hline Author & Number of specimens & $\begin{array}{l}\text { Classical (LGA,CHA,SA) } \\
\text { trifurcation }\end{array}$ & Variant \\
\hline Petrella (2007) & 89 & $82.02 \%$ & $17.98 \%$ \\
\hline Urugel(2009) & 100 & $89 \%$ & $11 \%$ \\
\hline Mburu (2010) & 123 & $61.8 \%$ & $38.2 \%$ \\
\hline $\begin{array}{l}\text { Present } \\
\text { study(2010) }\end{array}$ & 50 & $80 \%$ & $20 \%$ \\
\hline
\end{tabular}

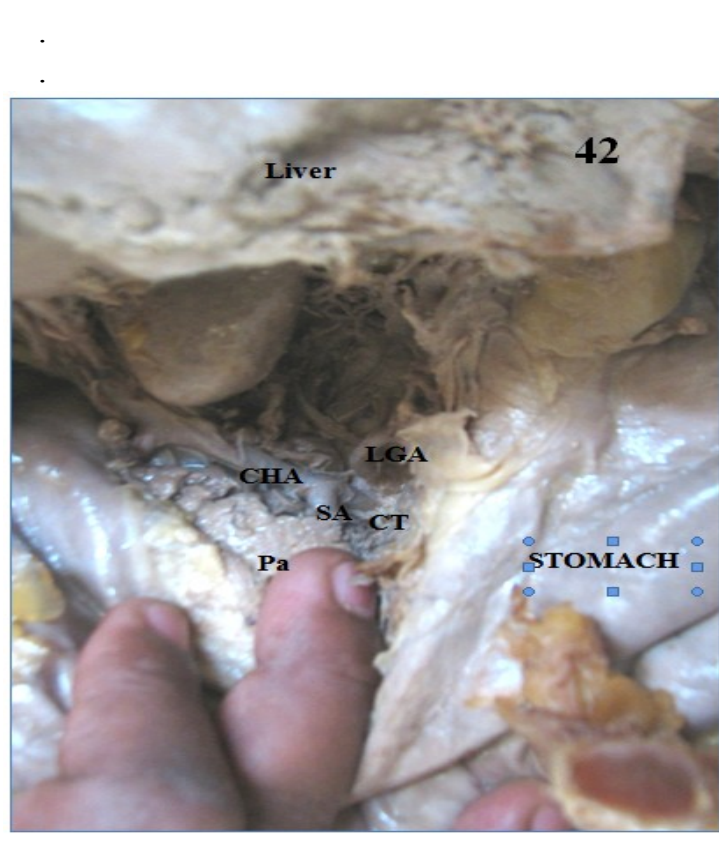

Fig 1: Bifurcation of coeliac trunk into common hepatic and splenic arteries. The left gastric artery was seen arising from the abdominal aorta.

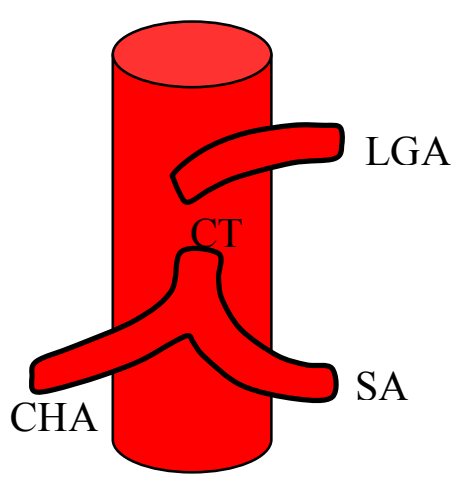

Fig 2: Diagrammatic representation of Fig 1 

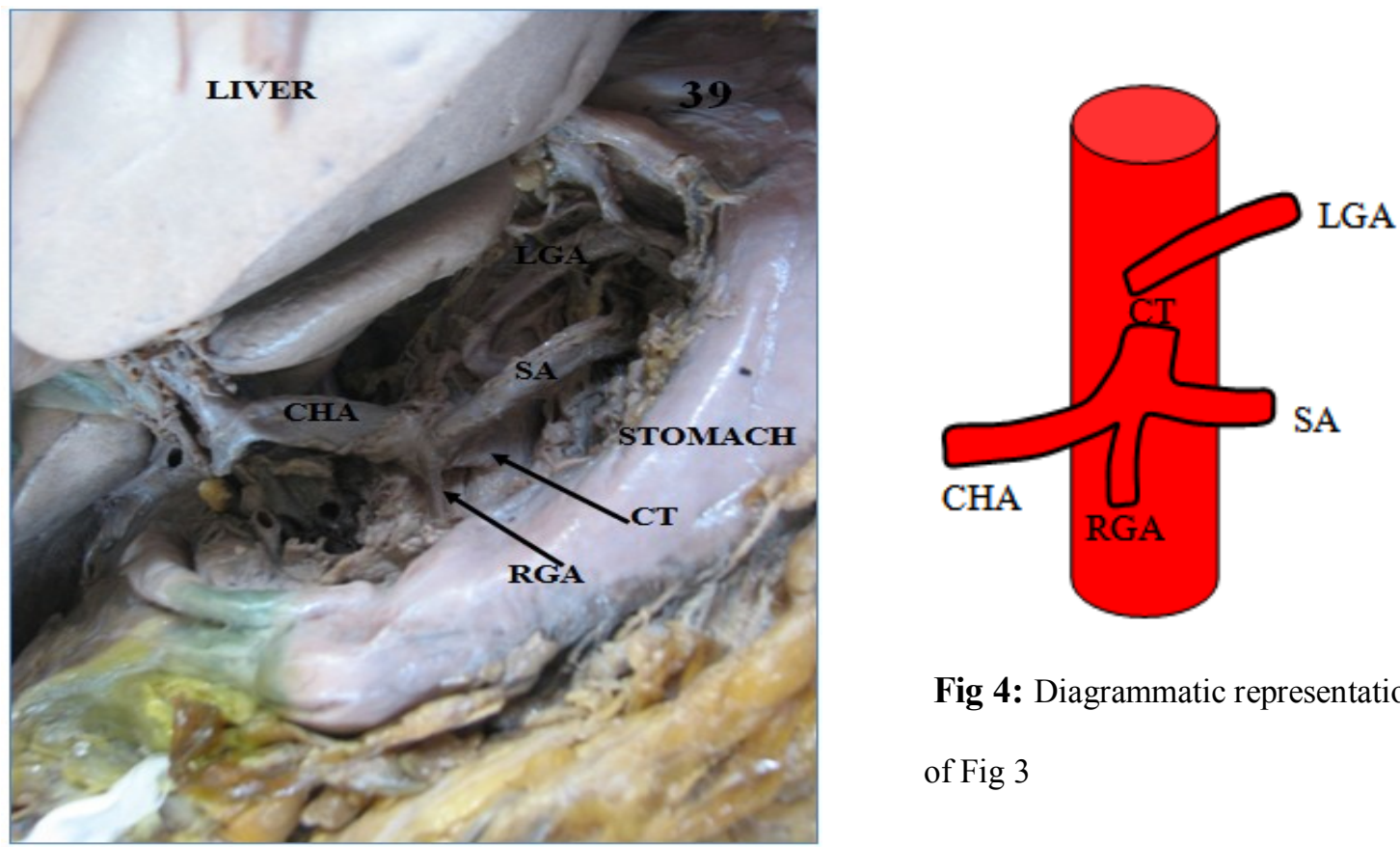

Fig 4: Diagrammatic representation of Fig 3

Fig 3: Variant trifurcation of coeliac trunk into common hepatic, splenic and right gastric arteries. The left gastric artery was seen arising from the abdominal aorta.

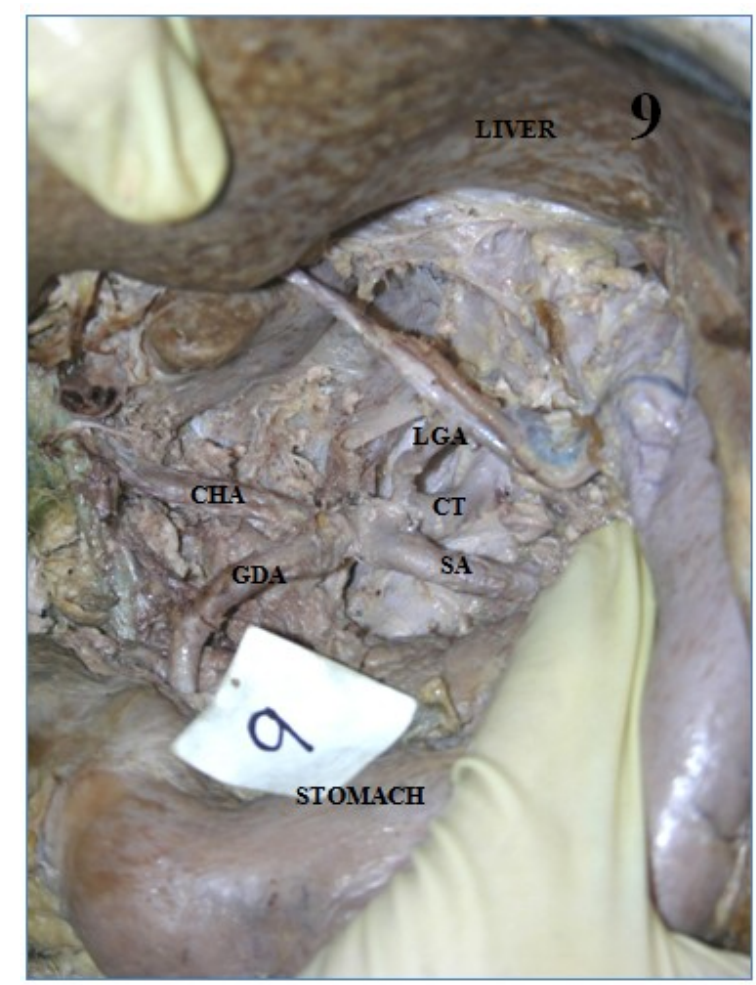

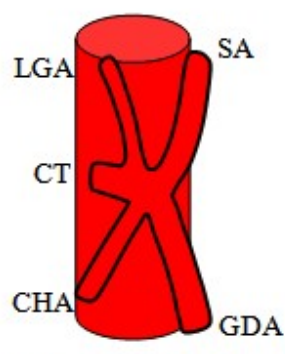

Fig 6: Diagrammatic representation of Fig 5

Fig 5: Quadrifurcation of coeliac trunk into common hepatic, splenic, left gastric and gastroduodenal arteries. 


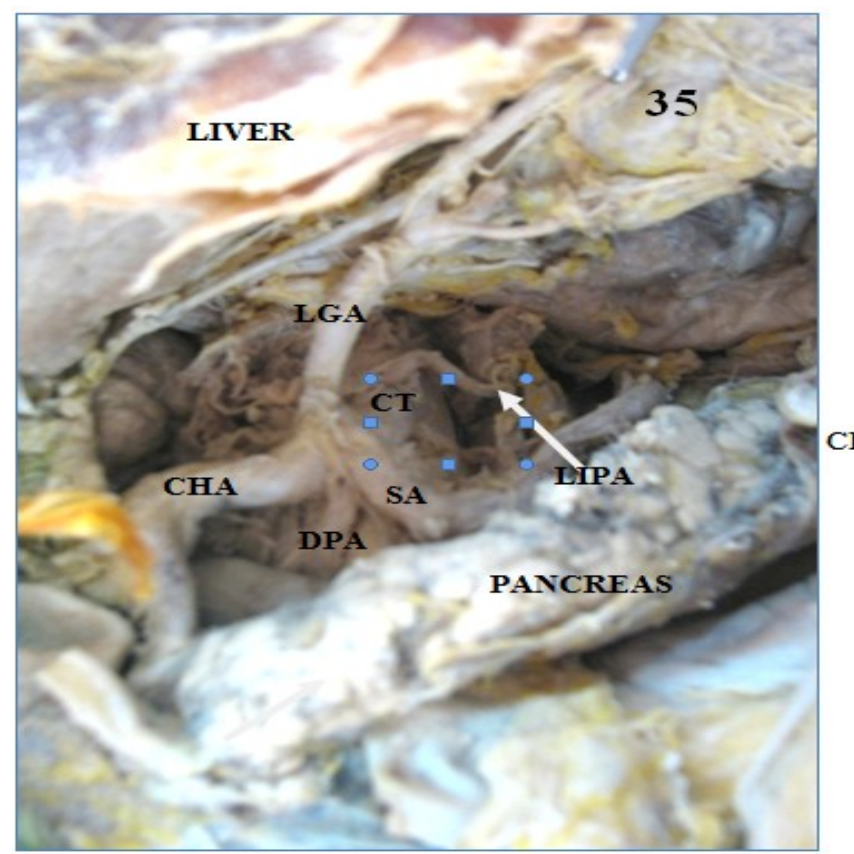

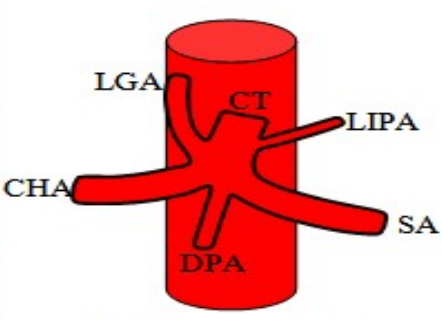

Fig 8: Diagrammatic

representation of Fig 7

Fig 7: Pentafurcation of the coeliac trunk into common hepatic, splenic, left gastric, dorsal pancreatic and left inferior phrenic arteries

\section{Legends for photos \& tables.}

CT-Coeliac Trunk

LGA- Left Gastric Artery

CHA- Common Hepatic Ar..ry

SA- Splenic Artery

Pa- Pancreas

RGA- Right Gastric Artery.

GDA- Gastroduodenal Artery.

DPA- Dorsal Pancreatic Artery

LIPA- Left Inferior Phrenic Artery. 